\title{
Job Discrimination and Ethics in the Workplace
}

\author{
PhD Cand.. Gentisa Furxhi \\ University "Fan S. Noli”, Econonic Faculty, Korca, albania \\ email: gfurxhi@gmail.com \\ Prof. as. dr. Sonela Stillo \\ University "Fan S. Noli", Econonic Faculty, Korca, Albania \\ sonelastillo@yahoo.com \\ Msc. Enslemvera Zake (Furxhi) \\ Head of Treasury Branch of Korca Region \\ email: eni_furxhi@yahoo.com
}

\begin{abstract}
Every society wants to have an ethical community. Although, that every citizen wants to be treated as equal, studies show that discrimination and gender inequality in employment relationships are present in every society, at any time. Discrimination is: treating a person or particular group of people differently, especially in a worse way from the way in which you treat other people, because of their skin color, sex, sexuality, etc ${ }^{1}$. Job discrimination is when institutional decisions, policies, or procedures are at least partially based on illegitimate forms of discrimination that benefit or harm certain groups of people. Developed societies have a lower rate of job discrimination than developing societies have. Although, it is unclear why in these societies with economic civilization and culture development, job discrimination still exists, when the right of employment is sanctioned and guaranteed by Labor Code and by specific laws. The most common forms of job discriminations are discriminations based on gender, race, ethnic origin, religion, age. New forms are based on disability, sexual orientation, genetics and lifestyle. Not all discrimination is intentional or conscious. Sometimes people favor some groups of people over others as a matter of personal preference, or unconsciously accept stereotypes. Whatever, job discrimination is intentional or it is conscious, it is always immoral. Job discriminations violates utilitarian, rights and justice principles of ethics. Our study is focused to see how much job discriminations is widespread in Albanian society. We will analyze forms of discriminations to have a clear view which are the most common job discriminations types in Albania. Also, we will figure out if employees who have been discriminated in the workplace, have reported this unethical behavior to their supervisor or at the relevant state bodies. At the end, we will see if there has been any punishment to those who use discrimination to the employees.
\end{abstract}

Keywords: job discrimination, ethics, discriminations forms.

\section{Intruduction}

The term discriminateappeared in the early 17th century in the English language. It is from the Latindiscriminat'distinguished between. So, discrimination in its root meaning is not at all wrong. It simply refers to the act of distinguishingone object from another. Today, this term (discrimination)refers to "wrongfuldiscrimination," or distinguishing among people on the basis of prejudice instead of individual merit. Job discrimination is when institutional decisions,

\footnotetext{
${ }^{1}$ Cambridge Dictionaries online 2016
} 
policies, or procedures are at least partially based on illegitimate forms of discrimination that benefit or harm certain groups of people. Discrimination in employment involves three basic elements'

It must be a decision not based on individual merit.

The decision must derive from racial or sexual prejudice.

The decision must have a harmful impact on the interest of employees

Discriminatory acts themselves can be categorized according to the extent to which they are

intentional and institutionalized. An act may be part of the isolated behavior of a single

individual who:

Intentionally discriminates based on personal prejudice.

An act may be part of the routine, institutionalized behavior of a group.

The act must intentionally discriminate out of personal prejudice

Discrimination, in an organization, exists when a disproportionate number of a certain group'smembers hold less desirable positions despite their preferences and abilities. Usually, there are madethree types of comparisons to provide if an organization is discriminatory:

comparisons of average benefitsgiven to various groups,

comparisons of the proportion of a group found in the lowest levels of the organizations,

comparisons of the proportion of a group found in the most advantageouspositions in the organization.

Job discrimination is when institutional decisions, policies, or procedures are at least partially based on illegitimate forms of discrimination that benefit or harm certain groups of people.

Developed societies have a lower rate of job discrimination than developing societies have. Although, it is unclear why in these societies with economic civilization and culture development, job discrimination still exists, when the right of employment is sanctioned and guaranteed by Labor Code and by specific laws. The most common forms of job discriminations are discriminations based on gender, race, ethnic origin, religion, age. New forms are based on disability, sexual orientation, genetics and lifestyle.

Not all discrimination is intentional or conscious. Sometimes people favor some groups of people over others as a matter of personal preference, or unconsciously accept stereotypes. Whatever, job discrimination is intentional or it is conscious, it is always immoral. Job discriminations violates utilitarian, rights and justice principles of ethics. Job discriminations violets utilitarian principle because it causes an inefficient use of human resources. Also, discrimination violatesbasichumanrights and it leads tounequaldistributionof rightsandobligationsamongst themembersof the society.

\section{Forms of discriminations}

Sex Discrimination- is when "people are treated differently because of their sex".

1"Job Discriminations: it's nature"; Business Ethics MGT610 pg.114 
Women have been for decades discriminated by society. They had lower salaries and they hold lowerjob positions than men. During the 20th century women gained rights and got equal status among men and there was a huge progress for women.

Different studies prove why women's paycheck is smaller. Most of the time women chose their

careers based on what they like. On the other hand, men chose future jobs based on high salary and status in society.

b) Age Discrimination- occurs when employees are treated less favorably because of their age. Older workers are always discriminated in the workplace, because it is believed that for older workers is harder to learn new things and they get sick more frequently. So, their employment is more expensive than younger workers.

c) Racial Discrimination- occurs when people are treated differently because of their race or color. Race discriminationcan bedirectorindirect. It may also take the form of harassment or victimization.

d) Disability discrimination- is when a person with a disability is treated less favorably than a person without the disability in the same or similar circumstances. It is also disability discrimination when there is a rule or policy that is the same for everyone but has an unfair effect on people with a particular disability.

e)Sexual orientation discrimination- refers to harassment or differential treatment based on someone's perceived or actual gay, lesbian, bi-sexual, or heterosexual orientation. Many workplaces, and even a number of states, have policies and laws against sexual orientation discrimination.

f) Lifestyle discrimination-Many employers attempt to control employees' private lives by firing people who smoke or drink in their own homes or engage in risky hobbies like motorcycle riding. The employer justified its decision on the ground thatthe consequences of the off-duty behavior in some way spill over to the workplace, affecting the employer's legitimate interests ${ }^{1}$.

\section{General framework of employment laws in Albanian Republic}

Constitution of the Republic of Albania sanctions the rights and fundamental freedoms as a guarantee and a fundamental element of democracy. The right to nondiscrimination in employment and the exercise and enjoyment of this right finds place in the Constitution, under which "No one can be discriminated against for reasons such as gender, race, religion, ethnicity, language, political, religious and philosophical, economic, educational, social, or ancestry ${ }^{2}$. The definition of gender discrimination is not provided in the Constitution, but in the Convention on "Elimination of All Forms of Discrimination against Women" as a UN Convention which was ratified by the Republic of Albania in 1993. ${ }^{3}$

The Labor Code of the Republic of Albania, approved by Law 7961, dated 12. 07. 1995, is based on fundamental constitutional principles. It respects international conventions ratified and internationally recognized rights. This code prohibits discrimination based on sex that affects an individual's right to be equal in employment and training, in the recruitment procedures and working conditions, in the performance of duties, in payment, in social assistance and termination of contract work, as well as in participation in trade unions.

Law no. 9970, dated 24. 07. 2008 "On Gender Equality in Albania", aims to provide effective protection from sex discrimination and any form of behavior that encourages discrimination because of sex, as well as to determine the necessary measures to guarantee equal opportunities between women and men, to eliminate discrimination based on sex, in any form that it appears.

\footnotetext{
${ }^{1}$ Stephen D. Sugarman "Lifestyle Discrimination in Employment”, Berkeley Journal of Employment \& Labor Law Volume 24,Issue 2,Article 9

2 Article 18, point 2 of the Constitution of the Republic of Albania

3 llirRusi "The Albanian legal framework on non-discrimination and gender equality in employment relationships", Academicus International Scientific Journal,
} 
Also, in Albania employees are organized in unions in order to protect their rights in workplace. These unions are protected by law. Labor law has been improved by the suggestions these unions have given time after time.

\section{Job discriminations in developed society}

Every society wants to have an ethical community. Although, that every citizen wants to be treated as equal, studies show that discrimination and gender inequality in employment relationships are present in every society, at any time. Developed societies have a lower rate of job discrimination than developing societies have. Although, it is unclear why in these societies with economic civilization and culture development, job discrimination still exists, when the right of employment is sanctioned and guaranteed by Labor Code and by specific laws.

Though the gap between men and women's wages is smaller for lower-wage earners, there is still a significant gender wage gap at all levels of the wage distribution, particularly at the middle and the top (see fig. 4. 1). To close this gender wage gap, women need to see wage growth faster than their male counterparts. Although women have seen modest wage gains in the last several decades, the main reason the gender wage gap has slowly narrowed is that the vast majority of men's wages have stagnated or declined. The best way to close the gender wage gap is for both men and women to see real wage increases, with women at a faster rate than men. ${ }^{1}$

According to anOctober 2014 report by the World Economic Forum examining gender equality across the world, the United States ranks 65 th in its survey of 142 countries, and earns a wage equality score of only 66 percent -- meaning women earn only two-thirds of what men earn for similar work. The report, which drew from nine years of data, found that there has been "only a small improvement in equality for women in the workplace" since they began surveying the issue, and predicted that women won't see full gender equality in the workplace until at least the year $2095^{2}$

Some data about earnings of women and men by race in USA for 2014 are given in the report of 2015 by U. S. Bureau of Labor Statistics (see fig. 4. 2). Asian women and men earned more than their White, Black, and Hispanic or Latino counterparts in 2014. Among women, Whites (\$734) earned 87 percent as much as Asian women (\$841), Blacks (\$611) earned 73 percent, and Hispanics ( $\$ 548$ ) earned 65 percent. In comparison, White men (\$897) earned 83 percent as much as Asian men (\$1,080); Black men (\$680) earned 63 percent as much; and Hispanic men (\$616), 57 percent.

\section{STATISTICS}

Earnings differences between women and men were the most pronounced for Asians and for Whites. Asian women earned 78 percent as much as Asian men in 2014,and White women earned 82 percent as much as their male counterparts. In comparison, Black and Hispanic women had median earnings that were 90 and 89 percent, respectively, of those of their male counterparts.

Women's earnings since 1979 have increased considerably across the major race and Hispanic ethnicity categories. Earnings growth has been greatest for White women. Between 1979 and 2014, inflation-adjusted earnings (also called constant-dollar earnings) rose by 31 percent for White women, compared with an increase of 19 percent for Black women and 15 percent for Hispanic women. In contrast, inflationadjusted earnings for White and Black men have been essentially flat, while Hispanic men's earnings declined by 8 percent since 1979. ${ }^{3}$

\section{Case study. Job discrimination in Albania}

The main aim of our study was to see how much job discrimination is wide spread in Albania business environment. Another goal was to realize which were the most frequent discriminations policies/practices used by businesses in workplace. We gathered data from 60 (sixty) businesses in total from 882 respondents, because $2 \%$ of respondents refused to collaborate.

\footnotetext{
1Alyssa Davis"Women Still Earn Less than Men Across the Board"; Economy Political Institute; April,2015

2 World Economic Forum, October 2014

${ }^{3}$ BLS Reports | November $2015 \cdot$ www.bls.gov 
$54 \%$ of businesses were production businesses and $46 \%$ were service businesses. $74 \%$ of respondents were employees and $18 \%$ were managers and $8 \%$ were CEO. Some of the most interesting datas of our study are shown below.

As we see from fig. 5. 1, 56\% of respondents have been discriminated during their years of work. This show that the major part of albanian businesses are discriminatory.

The most frequent types of discriminations were sex discrimination( 28\%) and age discrimination (15\%), (see fig. 5. 2. ). There were no sexual orientation discriminations, we belive that this is not because albanian society is not discriminatory in this point. But the real reason is that albanian people do not show free their sexual orientation because they are affraid from the society prejudices. Lyfestyle discrimination was based only on use of drugs and alcohol.

Although, a major part of respondents $(56 \%)$, have been discriminated in the workplace, in different ways, only $24 \%$ of them have reported this unethical and prohibiden behaviour( see fig. 5. 3). This is due to the fact, that albanian people to not really bealive in justice and they have fear to lose their job if they go against their employer.

The best part of respondents who have been discriminated have reported this fact to the staff (15\%),

( see fig. 5. 4. ) because they do not belive that the owner or the manager will act in a differently way. This is why only $2 \%$ reported to the business owner and $3 \%$ to their manager.

We think that the major reason why employees do not report their discrimination to the right bodies, is because they do not have relevant facts or colleagues who prove that they have been discriminated( see fig. 5. 5). Sometimes their not discriminated colleagues have fear to lose their job if they support these employees in their issue.

\section{Conclusions}

Discriminationand gender inequality in employment relationships are present in every society, at any time. Job discrimination is when institutional decisions, policies, or procedures are at least partially based on illegitimate forms of discrimination that benefit or harm certain groups of people. Developed societies have a lower rate of job discrimination than developing societies have. The most common forms of job discriminations are discriminations based on gender, race, ethnic origin, religion, age. New forms are based on disability, sexual orientation, genetics and lifestyle.

Not all discrimination is intentional or conscious. Sometimes people favor some groups of people over others as a matter of personal preference, or unconsciously accept stereotypes. Whatever, job discrimination is intentional or it is conscious, it is always immoral. Job discriminations violates utilitarian, rights and justice principles of ethics.

World Economic Forum examinedin 2014 gender equality across the world, found that there has been "only a small improvement in equality for women in the workplace.

Constitution of the Republic of Albania sanctions the rights and fundamental freedoms as a guarantee and a fundamental element of democracy. The right to nondiscrimination in employment and the exercise and enjoyment of this right finds place in the Constitution. The Labor Code of the Republic of Albaniaprohibits discrimination based on sex that affects an individual's right to be equal in employment and training, in the recruitment procedures and working conditions, in the performance of duties, in payment, in social assistance and termination of contract work, as well as in participation in trade unions.

Also, in Albania employees are organized in unions in order to protect their rights in workplace.

Although, there are good laws against discriminations in workplace, Albania society have to deal more with job discrimination, because as we saw from our study it is essentiallya discriminatory society. Most common forms of discriminations were sex and age discriminations. There were low rate of employees who reported their discriminations, because Albanian people do not really believe in justice and they have fear to lose their job if they go against their employer. 


\section{References}

Alyssa Davis" Women Still Earn Less than Men Across the Board"; Economy Political Institute; April,2015. http://www. epi. org/

Bureau of Labor Statistics, U. S. Department of Labor, "Women's earnings in 2014"; November 2015. www. bls. gov

Constitution of the Republic of Albania; Article 18, point 2.

Coleman, Major G. "Racial Discrimination In The Workplace: Does Market Structure Make A Difference?. " Industrial Relations 43. 3 (2004): 660-689. Business Source Complete. Web. 2 Dec. 2012.

Dessler, Gary. A framework for Human Resource Management. 5th. 1. New Jersey: Pearson, 2009; pg. 27-59.

HysenCela. "Etika e Biznesit", 2012

Gaskill, Dan. "Ethical and Social Problems in Contemporary Society. "CALIFORNIA STATE UNIVERSITY, SACRAMENTO. ;Web. 5 Dec 2012

IlirRusi "The Albanian legal framework on non-discrimination and gender equality in employment relationships", Academicus - International Scientific Journal, 2012

Jones, Dan. "Age Discrimination In The Workplace: A 2001 Survey Of Utah Residents Age 40. " Health, Baby Boomers, Election News, Over 50, Retirement Plan. AARP, Web. 5 Dec 2012.

Orpen, Christopher. "The Effects Of Race Of Applicant And Type Of Job On Hiring Decisions. " Journal Of Social Psychology 118. 2 (1982): 279. Business Source Premier. Web. 3 Dec. 2012.

ROBERTS, PAULINE. "Employers' Liability For Sexual And Racial Harassment: Developing The Reasonably Practicable Steps Defense. " Industrial Law Journal30. 4 (2001): 388-395. Business Source Complete. Web. 3 Dec. 2012

Stephen D. Sugarman "Lifestyle Discrimination in Employment",Berkeley Journal of Employment \& Labor Law; Volume 24, Issue 2,Article 9

World Economic Forum,"Hourly wages by gender and percentile, 2014" October 2014

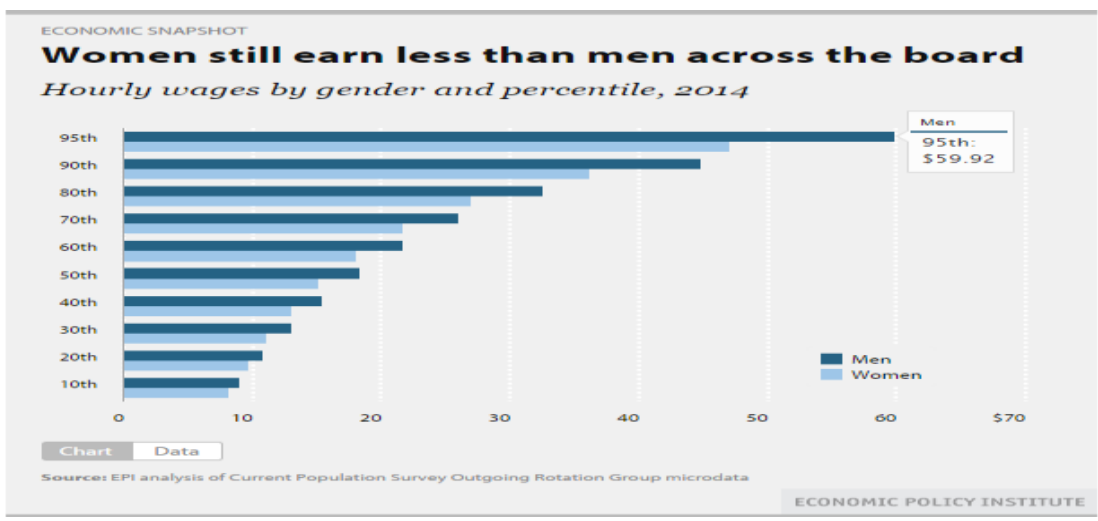

Fig4. 1: Hourly wages by gender and percentile, 2014 


\section{Median usual weekly earnings of women and men who are full-time wage and salary workers, by race and Hispanic or Latino ethnicity, 2014 annual averages}

\section{Women}
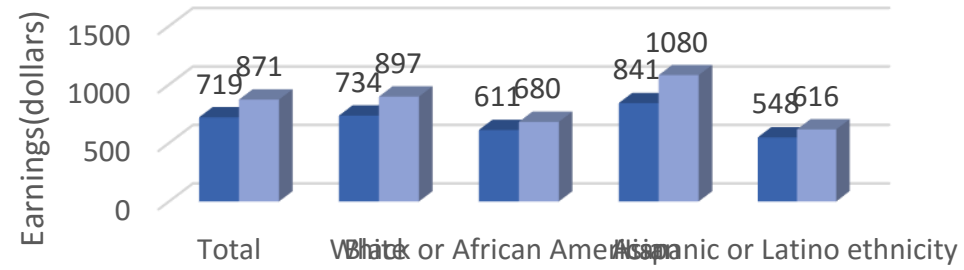

Source: U.S. Bureau of Labor Statistics.

Fig. 4. 2: Weekly earnings of women and men who are full-time wage and salary workers, by race and Hispanic or Latino ethnicity.

\section{Have you ever felt discriminated by your employer?}

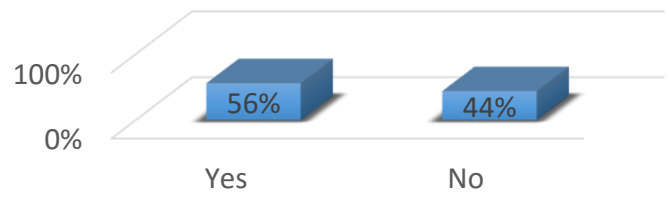

Fig. 5. 1. Employer dicriminations to employees.

Reasons why respondents have been discriminated

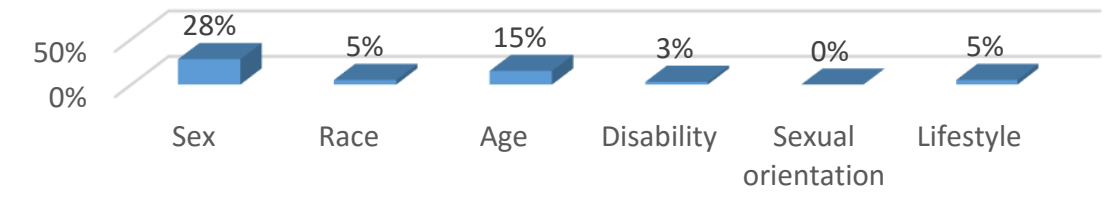

Fig. 5. 2. Types of job discriminations in albanian businesses. 
Have you reported discrimination to someone?

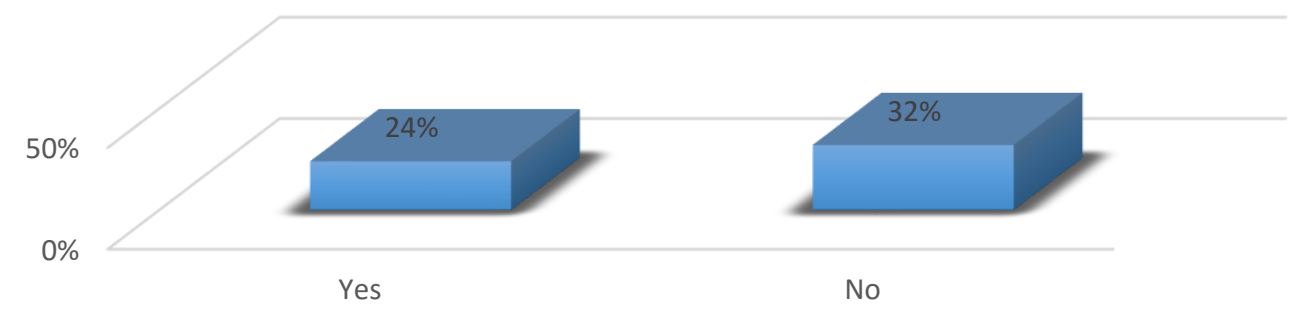

Fig. 5. 3. How job discrimination is reported

To whom you

have reported about your discrimination?

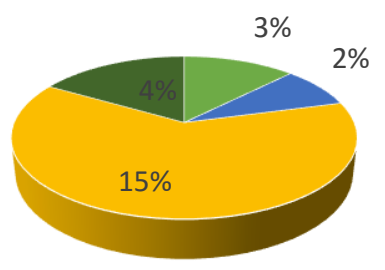

- Manager

- Owner

- Staff

- Supervisor

Fig. 5. 4. Employees reported their discirimination to owner, manager, staff, ect.

Do you have colleagues or facts that prove that you have been discriminated in the workplace?

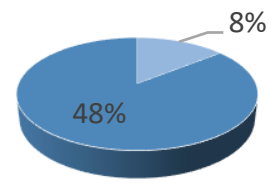

Fig. 5. 5: Facts or collegaues that prove that employees have been discriminated 